\title{
Expression and Clinical Significance of KISS-1 and TIMP-1 in Colon Carcinoma
}

\author{
Yanxin Zhang ${ }^{1, \text { a }}$, Yan Zhao ${ }^{1, \text { b }}$ \\ ${ }^{1}$ Luohe Medical College, Luohe, Henan, China, 462002 \\ ${ }^{\mathrm{a}}$ email, ${ }^{\mathrm{b}}$ email
}

Keywords: Colon Carcinoma, KISS-1, TIMP-1, Occurrence, Development, Invasion, Metastasis

\begin{abstract}
Objective: To detect the expression of KISS-1 and mRNA TIMP-1 and protein in colon carcinoma, and to explore its clinical significance. Methods: The application of Realtime PCR was detected in 45 cases of colon carcinoma, adjacent atypical hyperplasia and normal colonic mucosa in KISS-1 and the expression of TIMP-1mRNA, SP method was used to detect KISS-1 and TIMP-1 protein expression, correlation analysis, and its occurrence and development of colon cancer invasion and metastasis and the relationship between the two. Results: The KISS-1mRNA and protein expression in normal colon mucosa, atypical hyperplasia and carcinoma were gradually decreased, there were significant differences between the groups $(\mathrm{P}<0.05)$; the expression of KISS-1mRNA and protein and colon cancer invasion and lymph node metastasis $(\mathrm{P}<0.05)$. The TIMP-1mRNA and protein expression in normal colon mucosa, atypical hyperplasia and carcinoma was also decreased, the difference between groups was statistically significant $(P<0.05)$; the expression of TIMP-1mRNA protein in colon carcinoma and invasive depth and lymph node metastasis $(\mathrm{P}<0.05)$. The protein expression was positively correlated. Conclusion: The expression of KISS-1, TIMP-1mRNA and protein is closely related to the occurrence, development, invasion and metastasis of colon cancer.
\end{abstract}

Colorectal cancer is one of the most common malignant tumors, the incidence increased gradually in recent years, and the age of onset is becoming younger, high mortality, research shows that the biological behavior of colon cancer. This study uses Realtime PCR and SP method in 45 cases of colon carcinoma, adjacent atypical hyperplasia and normal mucosa of colon tumor metastasis suppressor gene KISS-1 and matrix metalloproteinase inhibitors (tissue inhibitor, of metallo-proteinase1, TIMP-1) mRNA and protein expression, the objective is to investigate KISS-1 and TIMP-1 in colorectal cancer the development and invasion and metastasis of the role for the further study of colon cancer occurrence, development and invasion and metastasis mechanism and to find effective way to provide theoretical foundation of inhibiting the invasion and metastasis of colon cancer.

\section{Materials and Method}

Sample Treatment. Collected in Luohe Central Hospital from September 2014 to January 2016 surgery fresh tissue specimens from 45 patients were selected for colon cancer tumor, tumor and normal tissue at the junction and $5 \mathrm{~cm}$ away from the tumor than normal colon mucosa, stored in liquid nitrogen. In 45 patients, male 34 cases, female 11 cases, aged 36 to 78 years old, average age $(58.38+10.96)$ years old. All patients did not receive chemotherapy, radiotherapy and immunotherapy before operation. Diagnosis and classification of colorectal cancer according to the provisions of node cancer cooperative group of Pathology, pathologically diagnosed, 45 cases were adenocarcinoma, 23 cases of adjacent mucosa showed severe atypical hyperplasia, 21 cases of $5 \mathrm{~cm}$ 
away from the tumor than normal colonic mucosa. In 45 cases of colon cancer, there were 23 cases with lymph node metastasis and 22 cases without metastasis group. According to the depth of invasion, 14 cases of superficial muscular layer, 15 cases of deep muscular layer and 16 cases of outer membrane. When the paraffin tissue samples after $10 \%$ formalin fixed, paraffin embedded, 4 $\mathrm{m}$ thick serial sections, to use by routine pathology and immunohistochemistry.

Main Reagent and Immunohistochemical Staining. Sheep anti human KISS-1 monoclonal antibody purchased from the United States DAKO company, Rabbit anti human TIMP-1 polyclonal antibody purchased from Beijing Chinese fir. The staining procedure was carried out strictly according to the specification, and the positive control of KISS-1 and TIMP-1 were used as the positive control of the colon and liver respectively. The PBS solution was used as the negative control. Real time fluorescence quantitative PCR (Realtime PCR) was purchased from Beijing gold biotechnology company, KISS-1 gene primers synthesized by Beijing three Bo Polygala Gene Technology Co Ltd.

Test of RT-PCR and Expression of KISS-1 and TIMP-1 mRNA. KISS-1 primer is 5'-ACCTGGCTTCTCACCAAG-3', and the downstream primer is 5'-CCC GGATGATACACGGTCCG-3', about 201bp in size, annealing temperature of 60 DEG C; TIMP-1 upstream primer 5'-CATGGAGAGCCTCTGTGGA-3'and downstream primer is 5'GTTCAGGCTTCAGCTTTTG-3', the size is about 392bp, the annealing temperature of 59.5 DEG C; GADPH upstream primer 5'-TGGCAAAGTGGAGATTGTT-3'and downstream primer is 5'TAGTGACGGTGGGTCTTC-3', about 484bp in size, annealing temperature 58 C. 94 degree of pre denaturation 2min, 1 cycles; 94 degrees denaturation 30s, annealing 30s, 72 degrees $C$ extension of $2 \mathrm{~min}$, a total of 35 cycles. EB staining was observed under the ultraviolet ray casting apparatus. The results were observed under the ultraviolet transmission analyzer. The D-140 image recording and analysis system was used to record the expression of KISS-1 and mRNA quantity. The software of quantity one was used to analyze the expression of the system.

Immunohistochemistry Results and Judgment Criteria. KISS-1 and staining of TIMP-1 positive signal located in the cytoplasm, brownish yellow granules, and strong color brown. In accordance with the proportion of positive cells: score $<10 \% 1$ points, from $10 \%$ to $50 \%$ with 2 points, 3 points more than $50 \%$; according to the staining intensity score: negative 0 points, pale yellow staining was 1 , moderate yellow staining is 2 points, 3 points for the brown staining. With two of the product of total score: $<33<<$ total score is negative, 6 positive, the total score of more than 6 strong positive.

Statistical Analysis. All data were analyzed by statistical software SPSS17.0, using 2 test, t test and Spearman rank correlation analysis, $\quad \alpha=0.05$ level test.

\section{Results}

Expression of KISS-1 Protein. The protein expression rate of KISS-1 in normal colonic mucosa, adjacent atypical hyperplasia and carcinoma tissues were 90.48\% (19/21), 60.87\% (14/23) and $35.56 \%$ (16/45) respectively. The expression rate of KISS-1 protein in cancer tissues was significantly higher than that in normal colonic mucosa and adjacent normal colonic mucosa, and the difference was statistically significant $(\mathrm{P}<0.05)$. Expression of KISS-1 protein in colon carcinoma tissues with different pathological characteristics was shown in Table 1.

Expression of TIMP-1 Protein. The protein expression rate of TIMP-1 in normal colonic mucosa, adjacent atypical hyperplasia and carcinoma tissues were 95.24\% (20/21), 65.22\% (15/23) and $40 \%$ (18/45) respectively. The expression rate of TIMP-1 protein in cancer tissues was significantly different from that of normal colonic mucosa and adjacent normal colonic mucosa (22), 
and the difference was statistically significant $(\mathrm{P}<0.05)$. Expression of TIMP-1 protein in colon carcinoma with different pathological characteristics was shown in Table 1.

Table 1 Expression of KISS-1 protein and TIMP-1 protein in tissues of normal colonic mucosa, atypical hyperplasia and colon cancer

\begin{tabular}{|c|c|c|c|c|c|c|c|c|c|}
\hline \multirow[b]{2}{*}{ group } & \multirow[b]{2}{*}{$\begin{array}{c}\text { total } \\
\text { cases }(n)\end{array}$} & \multicolumn{4}{|c|}{ KISS-1 } & \multicolumn{4}{|c|}{ TIMP-1 } \\
\hline & & $\begin{array}{l}\text { positive } \\
\text { cases } \\
\mathrm{n}\end{array}$ & $\begin{array}{l}\text { positive } \\
\text { percent } \\
(\%)\end{array}$ & $\chi^{2}$ & $P$ & $\begin{array}{l}\text { positive } \\
\text { cases } \\
\mathrm{n}\end{array}$ & $\begin{array}{l}\text { positive } \\
\text { percent } \\
(\%)\end{array}$ & $\chi^{2}$ & $P$ \\
\hline $\begin{array}{l}\text { normal colonic } \\
\text { mucosa }\end{array}$ & 45 & 43 & 95.56 & & & 44 & 97.78 & & \\
\hline $\begin{array}{l}\text { atypical } \\
\text { hyperplasia }\end{array}$ & 45 & 28 & 62.22 & 16.76 & 0 & 29 & 64.44 & 17.56 & 0 \\
\hline $\begin{array}{l}\text { colon cancer } \\
\text { depth of } \\
\text { infiltration }\end{array}$ & 45 & 16 & 35.56 & & & 18 & 40 & & \\
\hline superficial muscle & 14 & 8 & 57.14 & & & 9 & 64.29 & & \\
\hline depth muscle & 15 & 7 & 46.67 & 9.652 & 0.008 & 7 & 46.67 & 8.76 & 0.013 \\
\hline membrane & 16 & 1 & 6.25 & & & 2 & 12.5 & & \\
\hline $\begin{array}{l}\text { lymph node } \\
\text { metastases }\end{array}$ & & & & & & & & & \\
\hline yes & 22 & 4 & 18.18 & 567 & 0.17 & 5 & 22.73 & 5351 & 0101 \\
\hline no & 23 & 12 & 52.17 & 0.07 & 0.017 & 13 & 56.52 & 5.J51 & 0.021 \\
\hline
\end{tabular}

Correlation between KISS-1 Protein Expression and TIMP-1 Protein Expression. The positive expression of KISS-1 in 16 cases of colon cancer in 12 cases of TIMP-1 positive expression; 23 cases of TIMP-1 negative expression in 29 cases of colon cancer KISS-1 negative expression by Spearman rank correlation analysis, $\mathrm{r}=0.531, \mathrm{P}<0.01$. There was a positive correlation between the expression of two in colon cancer tissues.

Table 2 Correlation between KISS-1 protein expression and TIMP-1 protein expression in tissues of colon cancer

\begin{tabular}{|c|c|c|c|c|c|}
\hline \multirow{2}{*}{ TIMP-1 } & \multicolumn{2}{|c|}{ KISS-1 } & \multirow{2}{*}{$r$} & \multirow{2}{*}{$P$} & \multirow{2}{*}{ sum } \\
\hline & + & - & & & \\
\hline+ & 12 & 6 & & & 18 \\
\hline- & 4 & 23 & 0.531 & 0 & 27 \\
\hline sum & 16 & 29 & & & 45 \\
\hline
\end{tabular}

KISS-1 and TIMP-1 mRNA Expression. The normal colonic mucosa, atypical hyperplasia, carcinoma KISS-1mRNA, TIMP-1 expression levels of mRNA were decreased, there were significant differences among the groups ( $\mathrm{P}<0.05)$; KISS-1mRNA, TIMP-1 mRNA expression in atypical hyperplasia tissues were lower than normal colonic mucosa, a significant difference between the two groups (all $\mathrm{P}<0.05$ ); the details are shown in Table 3. 
Table 3 KISS-1 and TIMP-1 mRNA expression in different tissues

\begin{tabular}{lcc}
\hline \multicolumn{1}{c}{ group } & KISS-1 & TIMP-1 \\
\hline normal colonic & $0.561 \pm 0.39$ & $0.631 \pm 0.25$ \\
$\begin{array}{l}\text { mucosa } \\
\text { atypical hyperplasia }\end{array}$ & $0.432 \pm 0.42^{\Delta}$ & $0.542 \pm 0.19^{\Delta}$ \\
colon cancer & $0.235 \pm 0.17^{*}$ & $0.316 \pm 0.26^{*}$ \\
\hline
\end{tabular}

KISS-1 and TIMP-1 mRNA Expression in Cancer Tissues of Different Clinical Features. Normal colonic mucosa, atypical hyperplasia, carcinoma KISS-1mRNA, TIMP-1 expression levels of mRNA were decreased, there were significant differences among the groups $(\mathrm{P}<0.05)$; KISS-1mRNA, TIMP-1 mRNA expression in atypical hyperplasia tissues were lower than that of normal colonic mucosa, a significant difference between the two groups (all $\mathrm{P}<0.05$ ); the details are shown in Table 4.

Table 4 KISS-1 and TIMP-1 mRNA expression in cancer tissues of different clinical features

\begin{tabular}{|c|c|c|c|}
\hline clinical features & cases（n) & KISS-1 & TIMP-1 \\
\hline \multicolumn{4}{|l|}{ depth of infiltration } \\
\hline superficial muscle & 14 & $0.365 \pm 0.26$ & $0.403 \pm 0.19$ \\
\hline depth muscle & 15 & $0.223 \pm 0.18^{\triangle}$ & $0.302 \pm 0.28^{\triangle}$ \\
\hline outer membrane & 16 & $0.216 \pm 0.22^{\triangle}$ & $0.286 \pm 0.23^{\triangle}$ \\
\hline lymph & & & \\
\hline \multicolumn{4}{|l|}{ metastases } \\
\hline yes & 22 & $0.216 \pm 0.25$ & $0.302 \pm 0.25$ \\
\hline no & 23 & $0.398 \pm 0.19^{*}$ & $0.401 \pm 0.19^{*}$ \\
\hline
\end{tabular}

Note: the leaching and adventitia group, deep muscle layer group compared with leaching and shallow muscle layer group, $\mathrm{P}<0.05$; no lymph node metastasis group and lymph node metastasis group, $\mathrm{P}<0.05 *$

\section{Discussion}

This study suggests that the research on the expression of KISS-1 and TIMP-1mRNA and protein can be used as a probe in tumor invasion and metastasis mechanism provides a new theoretical basis, the results of the study suggest that the two combined detection can be used as a predictor of malignant tumor invasion and metastasis, the expression of the two patients with invasion and metastasis may be combined. The specific mechanism of the interaction between the two in the occurrence, development, invasion and metastasis of colon cancer remains to be further studied.

\section{References}

[1] Kotani M, Detheux M, Vandenbogaerde A, et al., J Biol Chem, Vol. 276 (2001) No 37, p. 34631-34636

[2] Guedez L,Martinez A,Zhao S, et al., Blood, Vol. 105 (2005) No 4, p. 1660-1668

[3] Gomez D E, Alonso D F, Yoshiji H, et al., Eur J Cell Biol, Vol. 74 (1997) No 4, p. 111-122

[4] Kadirvel R, Dai D, Ding Y H, et al., AJNR Am J Neuroradiol, Vol. 28 (2007) No 5, p. 849-856

[5] Hori A, Honda S, Asada M, et al., Biochem Biophys Res Commun, Vol. 286 (2001) No 5, p. 958-963 